Ich finde:

und hiermit:

$$
A_{1-\mathrm{I}}=-1 \mathrm{1124489} 7959^{2} \quad B_{i-\mathrm{I}}=-11.7784^{2} 56560
$$

$$
\mathcal{F}_{\mathrm{I}, 4}^{4}=+0.0090628713
$$

in genügender Uebereinstimmung mit dem ron Bessel gefundenen Werthe.

Wien 1883 September 21 .

N. Herz.

\title{
Sulla apparenza della cometa Pons-Brooks.
}

La sera del 26 rivedi la cometa completamente mutata dall ultima osservazione fatta colla luna e quasi invisibile.

Il nucleo era incertissimo; parveni vedere al suo posto alcuni puntini lucidi; la nebulosità viva, circolare, uniforme costituiva la cometa, che palesavasi come un oggetto cospicuo nel cannocchiale di $25 \mathrm{~cm}$. Era visibile e nettamente con un tre pollici. Esaminando attentamente lungo il parallelo percorso dalla cometa notai un indizio certo di coda seguente per circa $15^{\prime}$, e a $10^{\prime}$ dalla cometa un rinforzo di questo indizio di coda in modo da parere materia cosmica staccata.

Roma 1883 Sett. 28.

\section{E. Milloserich.}

\section{Beobachtung des Cometen Pons-Brooks.}

\section{A uf der Sternwarte in Strassburg.}

Da das Wetter ziemlich trostlos ist und nicht bald weitere Beobachtungen des Cometen zu gestatten rerspricht, so erlaube ich mir, Ihnen die beiden letzten noch nicht mitgetheilten Beobachtungen noch einzusenden:

$$
\begin{aligned}
& \text { Sept. } 28 \quad 8^{\mathrm{h}} 14^{\mathrm{m}} 4^{\mathrm{s}} \text { M. Z. Strassburg } a \text { app. }={ }_{16^{\mathrm{h}} 26^{\mathrm{m}} 6^{\mathrm{i}} 27} \delta \text { app. }=+59^{\circ} 28^{\prime} 54^{\prime} 7 \\
& \mathrm{Vgl} * 10^{\mathrm{m}} \quad a{ }_{1} 883.0=\mathrm{I}^{\mathrm{h}} 25^{\mathrm{m}} 4 \mathrm{I}^{\mathrm{s}} .83 \quad \delta \mathrm{r} 88.3 .0=+59^{\circ} 37^{\prime} 30^{\prime \prime} 8 \text { Anschluss an AOe. } \mathrm{r} 6295
\end{aligned}
$$

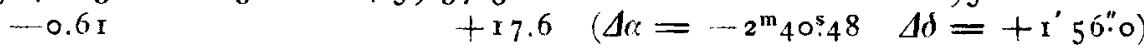

4 Vergleichungen; durch Cirrusgewölk bei einer kurzen Aufhellung des Himmels.

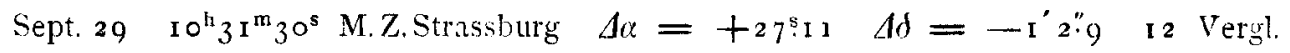

$$
\begin{aligned}
& \text { Vgl.* IO-I I }{ }^{\mathrm{m}} \text { stellam DM. } 59^{\circ} \text { I } 726 \text { sequens } 2^{\mathrm{m}} 37^{\mathrm{s}} \cdot 9^{8} \text { ad austr. } 6^{\prime} 32^{\prime \prime} \cdot 4
\end{aligned}
$$

(An den Ort von DM. $59^{\circ} 1726$ ist also anzubringen: $\Delta \alpha=+3^{\mathrm{m}} 5^{\mathrm{s} .09} \quad \Delta \delta=-7^{\prime} 35^{\prime \prime} 3$ ).

Die Coma hat einen Durchmesser von nahe 5 Minuten; der Kern liegt nicht mehr symmetrisch in ihrer Mitte und zwar erscheint die Coma im Positionswinkel $55^{\circ}$ etwas länger, als in der entgegengesetzten Richtung. Vom Ker $n$ aus ist in $p=55^{\circ}$ ein Schweifansatz sichtbar, welcher sich unverkennbar von der Coma abhebt. Der Kern ist von einer hellen etwa 40 Secunden breiten Hülle umgeben, welche nicht allmählich in die äussere Huille übergeht.

Strassburg i 883 Oct. I.

Ernst Hartwig.

$Z$ u s a t 2. Den Stern AOe. I6295 habe ich zweimal beobachtet:

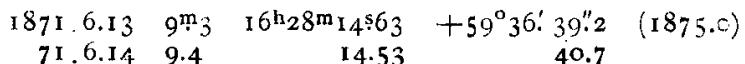

Der Stern $1 \mathrm{M} .+59^{\circ} 1726$ kommt als nicht programmmässig bei mir nicht vor.

Kr.

\section{Angelegenheiten der Centralstelle für astronomische Telegramme.}

Anlage zum Protocoll der Sitzung der Astronomischen Gesellschaft, Wien I883 Sept. I7.

\section{Berichterstatter: Herr Prof. Foerster.}

Die Commission für Astronomische Telegramme (kurzweg Telegramm.Commission benannt) hat sich in zwei Sitzungen am r6. Sept. hauptsächlich über folgende Punkte, welche ein allgemeines Interesse für die Gesellschaft haben, schlüssig gemacht:

r) Sie wird zunächst auf Grund ihres ersten Mandats die Geschäfte bis zu einer im Herbste 1885 zu ver- anstaltenden Versammlung im Correspondenzwege weiter fuhren, bis dahin etwaige Vacanzen ihrer Zusammen. setzung durch Cooptation ergänzen und alsdann den sämmtlichen Theilnehmern an der Centralstelle Kiel einen definitiven Entwurf der Statut-Bestimmungen, insbesondere in Betreff ihrer kunftigen Erneverung vorlegen. 